\title{
A RELAÇÃO DE ALUNOS DE FONOAUDIOLOGIA COM A LEITURA E ESCRITA A PARTIR DE UMA OFICINA DE LETRAMENTO
}

\author{
LA RELACIÓN DE LOS ESTUDIANTES DE FONOAUDIOLOGÍA CON LA LECTURA \\ Y ESCRITURA DE UM TALLER DE LETRAS
}

\section{SPEECH LANGUAGE THERAPY STUDENTS RELATIONSHIP WITH READING AND WRITING AFTER A LITERACY WORKSHOP}

Thiago Mathias PÔRTO ${ }^{1}$

Giselle Athayde MASSI ${ }^{2}$

Ana Cristina GUARINELLO ${ }^{3}$

\begin{abstract}
RESUMO: Pesquisas atuais apontam que atividades de letramento na universidade podem ampliar as possibilidades de relação dos sujeitos frente ao uso da leitura e escrita no ambiente acadêmico. Frente a tal compromisso, este estudo objetivou compreender a relação que discentes de uma IES estabelecem com a linguagem escrita após sua participação em uma oficina de letramento. Seis alunas de um curso de graduação em Fonoaudiologia que fizeram parte de uma oficina de promoção do letramento participaram deste estudo. Os resultados estão organizados em 2 eixos que retratam as "Dificuldades de leitura e escrita apresentadas pelos estudantes na universidade" e os "Efeitos da oficina de letramento na posição subjetiva dos mesmos". O espaço de oficina do letramento pode permitir que seus participantes assumam outras posições frente as suas supostas dificuldades, possibilitando a ampliação de sua autonomia, autoria e uma diminuição de suas angústias e sofrimentos frente à linguagem escrita.
\end{abstract}

PALAVRAS-CHAVE: Letramento. Letramento acadêmico. Ensino superior. Atividades grupais.

RESUMEN: Las investigaciones actuales apuntan que las actividades de alfabetización en la universidad pueden ampliar las posibilidades de la relación de los sujetos con respecto al uso de la lectura y la escritura en el entorno académico. Frente a tal compromiso, este estudio tuvo como objetivo comprender la relación que los estudiantes de una IES establecen con el lenguaje escrito, desde la perspectiva de los propios estudiantes desde su participación en un taller de letras. Seis estudiantes de un curso de pregrado en Logopedia que formaron parte de un taller de promoción de la alfabetización participaron en este estudio. Los resultados se organizan en 2 ejes que retratan las "dificultades de lectura y escritura presentadas por los

${ }^{1}$ Universidade Tuiuti do Paraná (UTP), Curitiba - PR - Brasil. Doutorando no Programa de Pós-graduação em Distúrbios da Comunicação. ORCID: https://orcid.org/0000-0003-4297-0382. E-mail: thiagomathiasoliveira@outlook.com.br

${ }^{2}$ Universidade Tuiuti do Paraná (UTP), Curitiba - PR - Brasil. Professora Adjunta no Programa de Pósgraduação em Distúrbios da Comunicação. Doutorado em Linguística (UFPR). ORCID: https://orcid.org/00000003-49129633. E-mail: giselle.massi@utp.br

${ }^{3}$ Universidade Tuiuti do Paraná (UTP), Curitiba - PR - Brasil. Professora Adjunta no Programa de Pósgraduação em Distúrbios da Comunicação. Doutorado em Estudos Linguísticos (UFPR). ORCID: https://orcid.org/0000-0002-6954-8811.E-mail: ana.guarinello@utp.br 
estudiantes en la universidad" y los "efectos del taller de alfabetización sobre su posición subjetiva". El espacio del taller de alfabetización puede permitir a sus participantes asumir otras posiciones frente a sus supuestas dificultades, permitiendo la expansión de su autonomía, autoría y una reducción de su angustia y sufrimiento frente al lenguaje escrito.

PALABRAS CLAVE: Alfabetización. Alfabetización académica. Enseñanza superior. Actividades grupales.

ABSTRACT: Current research explain that literacy activities developed inside the university can expand reading and writing possibilities of individuals in their academic environment. This study aimed to comprehend the relationship that students from an EIS establish with written language after their participation in a literacy workshop. Six students from an undergraduate Speech Language Therapy course, who participated in a literacy promotion workshop, were the subjects in this study. The results are organized in 2 axes: "Reading and writing difficulties presented by students at the university" and "Effects of the literacy workshop on their subjective position". The literacy workshop allowed these participants to assume different positions about their supposed writing difficulties, enabling the expansion of their autonomy, authorship and a reduction of their negative feelings about written language.

KEYWORDS: Literacy. Academic literacy. University education. Group activities.

\section{Introdução}

Desde o final do século XX, o Brasil vem sendo marcado por um processo de democratização no ensino, especialmente no que se refere ao acesso ao Ensino Superior (ES). Estatísticas do último Censo de Educação Superior, realizado em 2018, apontam um crescimento de $6,8 \%$ no número de ingressantes, em relação ao ano anterior. Além disso, em 2018 matricularam-se 8,5 milhões de alunos no ES, o que corresponde a um aumento de 44,8\%, em relação ao ano de 2008.

Entretanto, apesar de dados estatísticos indicarem expressivo aumento no número de discentes que ingressam em Instituições de Ensino Superior (IES), é prudente ressaltar que parcela significativa desses ingressantes não conclui sua formação, em grande medida, pelas restritas condições de letramento que apresentam (DONIDA; SANTANA, 2019). Nesse sentido, é preciso considerar alguns fatores envolvidos nessa conjuntura, evitando uma análise superficial da situação, que leva de forma simplista a explicações causais que recaem ora sobre o aluno, ora sobre sua família, ora sobre a noção de normalidade constituída a partir da equiparação social de comportamentos, valores, conhecimentos, produzindo um discurso que fortalece a normalização do agir e do pensar (CANGUILHEM, 2007). Giroto et al. (2019, p.809), a esse respeito, explicam que a partir desse conceito não há espaço para aquilo que é 
singular, assim, os diferentes modos de apropriação do conhecimento são, no campo da educação, muitas vezes entendidos "como sintomas de doenças, num processo de naturalização das diferenças e individualização de questões que perpassam a apropriação da linguagem escrita". É preciso considerar, segundo as autoras, que muitos dos discursos a esse respeito produzidos no campo da educação não deveriam ser reduzidos a aspectos individuais e orgânicos, já que tem relação direta com outros determinantes sociais, políticos, ideológicos, econômicos, culturais e produzem as desigualdades sociais. Essa noção de normalidade, ao transformar questões não médicas, de origem social, política, ideológica, em questões médicas e individuais produz uma medicalização, ou seja, trata questões sociais como se fossem biológicas, igualando o mundo da vida ao mundo da natureza (MOYSÉS; COLLARES, 2013).

Marquesin e Benevides (2011) e Winiarski (2018) explicam que muitas das dificuldades de leitura e de escrita manifestadas pelos alunos do ES ocorrem devido a lacunas do próprio sistema básico de ensino. Pois, na visão das autoras, o trabalho escolar não tem sido suficientemente capaz de conduzir os estudantes a fazerem uso significativo da linguagem em seu cotidiano por meio de práticas sociais, assim, muitas escolas acabam por frequentemente usar práticas mecânicas e descontextualizadas, tais como cópias, ditados e atividades que enfatizam apenas a dimensão normativa da língua em detrimento de questões textuais e discursivas.

Ainda, acerca das condições de letramento de estudantes do ES, estudos de Moretto (2017) e Souza e Bassetto (2014) evidenciam uma distância entre as expectativas dos docentes, as práticas acadêmicas propostas e as condições de leitura e escrita dos discentes. Pesquisas da Abramundo (2014) e do INAF (2016) revelam que discentes ingressantes, no ES, apresentam níveis de letramento insuficientes para operarem, significativamente, com os diversos gêneros acadêmicos que medeiam sua formação. Nessa direção, as IES que, em tese, deveriam propiciar o acesso à produção do conhecimento, ao exercício da cidadania e ao posicionamento argumentativo, na prática, muitas vezes, não dão conta dessas atividades (KERSCH; SANTOS, 2017; MARTINS, 2017; WINIARSKI, 2018).

Para reverter essa situação, discussões acerca do efetivo uso da leitura e da escrita têm demonstrado a influência que tais atividades assumem na permanência e no desempenho acadêmico de discentes do ES, na medida em que eles podem reconhecer sua posição ativa e responsiva (WINIARSKI, 2018; DONIDA; SANTANA, 2019). Martins (2017) e Kersh e Santos (2017) ressaltam que as restritas condições de letramento, no ES, devem ser consideradas e enfrentadas pelas IES. Pois é a partir desse enfrentamento que, afastando-se de 
uma visão medicalizadora, elas podem propor políticas e programas para garantir uma formação que, além de suprir o mercado de trabalho, permita aos alunos, por meio da linguagem, elaborar e organizar, com criticidade, conhecimentos sobre questões relevantes à atuação profissional.

Almeida e Pan (2017) afirmam que ações voltadas ao trabalho com a linguagem são importantes no ambiente universitário. Segundo as autoras, a universidade ao eleger a língua escrita do gênero acadêmico como única possibilidade de produção verbal acaba por silenciar a história dos estudantes, subjugando as práticas sociais que o constituíram antes de entrar na academia.

Nesse sentido, cabe ressaltar o papel da linguagem na promoção do letramento, pois é a partir da atividade dialógica, própria da linguagem, nos termos de Bakhtin (2003, 2006), que estudantes podem efetivamente participar das relações sociais pertinentes ao ambiente universitário. Com esse entendimento, o objetivo deste estudo é compreender, a partir da perspectiva de discentes de uma IES, a relação que eles estabelecem com a linguagem escrita a partir de sua participação em uma oficina de letramento.

\section{Percurso metodológico}

O relato de pesquisa aqui apresentado foi aprovado pelo Comitê de Ética e Pesquisa, número 69021617.9.000.804. Trata-se de um estudo que se configura como uma pesquisaintervenção, na medida em que une a pesquisa à ação/prática e, no processo interlocutivo, permite que o pesquisador assuma uma posição de não neutralidade. Esse tipo de pesquisa ressalta a importância da construção conjunta de um espaço de ressignificação de opiniões, assumindo um caráter ativo e transformador da realidade. Pauta-se em uma perspectiva dialógica do discurso, explicitada por Bakhtin (2003; 2006), e que tem como eixo central o dialogismo. Considera-se assim que o espaço da pesquisa é visto como lugar de produção de práticas discursivas, as quais oportunizam tanto a ressignificação do passado, quanto a abertura de um porvir. Nesse sentido, o presente estudo assume um viés de intervenção, buscando compreender dados da realidade a partir das relações que estabelece com os sujeitos participantes do estudo. Dessa forma, essa pesquisa pautada no princípio da alteridade percebe a relação entre o pesquisador e os participantes como condição essencial para seu desenvolvimento e assume que todo conhecimento é produzido historicamente e partilhado socialmente (MASSI et al., 2018). 
Participaram deste estudo seis discentes do curso de Fonoaudiologia de uma universidade localizada no Sul no Brasil, os quais fizeram parte de uma atividade de extensão organizada por duas fonoaudiólogas, professoras de um Programa de Mestrado e Doutorado em Distúrbios da Comunicação e da Graduação em Fonoaudiologia. Cabe esclarecer que discentes de todos os períodos da graduação em Fonoaudiologia foram convidados a participar dessa atividade de extensão, nomeada Oficina do Letramento no Ensino Superior. O objetivo desta Oficina era voltado à promoção de um espaço de diálogo, escuta e ampliação das experiências de leitura e escrita vivenciadas no contexto acadêmico. A atividade: Oficina do Letramento foi desenvolvida em encontros semanais, com duração de 90 minutos, durante os anos letivos de 2017 a 2019. Todos os participantes assinaram o termo de consentimento livre e esclarecido.

As participantes desta pesquisa são seis estudantes de Fonoaudiologia, reconhecidas pelos seguintes nomes fictícios:

Beatriz: 37 anos, sétimo período do curso de graduação, proveniente do ensino básico público. Participou da oficina durante 1 ano e meio. Antes de entrar na universidade explicita que não tinha uma boa compreensão do que lia e escrevia, costumava só copiar sem questionar.

Vânia: 38 anos, sétimo período do curso de Fonoaudiologia. Cursou o ensino básico público (fundamental I e II) e ensino médio na rede privada. Participou da oficina durante 1 ano e meio. Antes de entrar na universidade relembra que apesar de gostar de ler e escrever apresentava dificuldades nessa modalidade da linguagem.

Ana: 33 anos, sétimo período do curso de graduação, proveniente do ensino básico público. Participou da oficina do letramento durante 1 ano e meio. Antes de freqüentar o ensino superior lembra que era questionada pelos professores devido a sua falta de atenção para ler e falta de concentração para escrever.

Fernanda: 23 anos, sétimo período de graduação, proveniente do ensino básico público. Participou da oficina do letramento durante 1 ano e meio. Antes de entrar na universidade relembra que tinha dificuldades com a leitura e a escrita.

Luana: 29 anos, sétimo período de graduação, proveniente do ensino básico público. Participou da oficina do letramento durante 1 ano e meio. Relata que tinha algumas dificuldades no uso da linguagem escrita antes de entrar na universidade.

Claudia: 44 anos, sexto período de graduação, proveniente do ensino básico público. Participou da oficina do letramento por 2 anos. Relata que antes de frequentar a universidade 
tinha dificuldades para ir à escola, em vista disso, grande parte de seus trabalhos escolares apresentavam "erros".

Para cada encontro, na Oficina, foi realizado um planejamento que considerava o objetivo do trabalho, contando com a participação ativa e criativa dos estudantes, que refletiam sobre as práticas de leitura e escrita em seu contexto acadêmico. As principais atividades desenvolvidas durante os encontros basearam-se no uso significativo da linguagem escrita, dentre as quais cabe destacar: rodas de conversa, produções textuais e leituras coletivas.

No final do primeiro semestre de 2019, após participarem da oficina durante pelo menos um ano e meio, seis alunas do curso de Fonoaudiologia responderam oralmente e individualmente a uma entrevista semi-estruturada. As entrevistas ocorreram com dia e horário marcado e tiveram uma duração aproximada de 25 minutos. Cada entrevista foi gravada e depois transcrita, na íntegra, por um dos pesquisadores responsáveis. Tal entrevista, entendida como dispositivo enunciativo, capaz de incentivar as estudantes a produzirem textos, foi composta por indagações que visavam compreender a relação das estudantes com essa modalidade de linguagem e os efeitos da sua participação nas oficinas e na sua posição subjetiva frente à leitura e a escrita. Assim, tendo em vista esse entendimento, com a intenção de explicitar o contexto enunciativo em que se deu a entrevista, as questões norteadoras e as respostas elaboradas pelas estudantes são apresentadas na sequência.

\section{Resultados e discussão}

As produções discursivas elaboradas pelas estudantes estão organizadas em dois eixos. O primeiro eixo, reconhecido como "Relações com a linguagem escrita na universidade", contempla a compreensão das estudantes acerca do uso que fazem dessa modalidade de linguagem no ensino superior, bem como as causas atribuídas as ditas dificuldades nesse uso. O segundo, nomeado como "Efeitos da oficina de letramento na posição subjetiva dos participantes", apresenta produções discursivas relacionadas à visão de cada participante acerca de suas produções de leitura e escrita após a participação na oficina do letramento. 


\section{Primeiro Eixo: Relações com a leitura e escrita na universidade}

A fim de compreender a visão das participantes acerca das relações estabelecidas com a leitura e a escrita na universidade, foi perguntado a cada uma das estudantes acerca da sua relação com a linguagem escrita. Parte das respostas das participantes é apresentada na sequência.

Ler e não compreender; escrever e não compreender, questão normativa (um pouco); (Beatriz)

Ler por muitas vezes e não entender, não dar conta de escrever de forma clara. Não consigo expor as minhas idéias. Na escrita, é sempre o gênero textual, a organização. Na escrita eu sei a ideia, a ordem, o normativo, mas a elaboração é bem difícil. (Vânia)

Compreensão e dificuldades normativas. Sempre preciso retomar de alguma forma o que leio e escrevo, muitas vezes preciso de outra pessoa para me ajudar. (Ana)

Tenho dificuldade na compreensão tanto do que leio, quanto do que escrevo. (Fernanda)

Não tenho dificuldades com essa modalidade, são alguns receios, tipo, interpretar e compreender corretamente. (Luana)

São variadas as minhas dificuldades de leitura e escrita, compreensão. Me fazer entender e interpretação são as que mais me incomodam. (Cláudia)

Acompanhando as produções discursivas das estudantes, é possível afirmar que a maioria refere dificuldades para ler e escrever, as quais são justificadas a partir de questões normativas da língua, da falta de compreensão e organização textuais. Semelhante relação estabelecida entre estudantes e a linguagem escrita foi também considerada no estudo de Fuza, Fiad e Gomes (2015), que perceberam que os alunos universitários tendem a valorizar aspectos normativos da língua tendo a preocupação em se adequar às normas linguísticas e formais que caracterizam cada gênero.

Algumas estudantes também demonstram que, na sua visão, a escrita é a simples reprodução de um conhecimento, que se compõe por um conjunto de regras normativas, distantes de práticas discursivas, nas quais os enunciados são historicamente construídos a partir de duas forças distintas. Uma delas verificável a cada construção de sentido tende à diferenciação e a outra tende à reiteração, na medida em que as mesmas expressões são usadas em situações distintas. O estudo de Signor (2011) anuncia que a escrita não é um 
sistema de unidades linguísticas inertes, deste modo, não pode ser tomada como um código a ser reproduzido, a partir de um conjunto de normas. É preciso entender que a escrita é uma sistematização aberta e dependente de construções conjuntas de significações.

Distanciadas dessa relação com a linguagem, algumas estudantes mencionam dificuldades para compreender os textos e apresentar clareza naquilo que escrevem - Tenho dificuldade na compreensão tanto do que leio, quanto do que escrevo. Parece prevalecer nos enunciados considerados acima uma perspectiva reducionista de linguagem escrita, centrada em competências, especialmente normativas, em detrimento da compreensão da escrita como prática social discursiva, cuja apropriação se dá nas/pelas relações humanas constituídas a partir de práticas sociais (GIROTO; ARAUJO; VITTA, 2019).

Apenas uma estudante ao falar sobre sua relação com a linguagem escrita falou dos gêneros textuais - Na escrita, é sempre o gênero textual, a organização -, apesar disso, não fica evidente, no relato, se a estudante possui a compreensão de que os gêneros possuem características próprias e peculiaridades estruturais, discursivas e pragmáticas. Segundo Bakhtin (2003), os gêneros discursivos são diversos e têm infinitas possibilidades, uma vez que são composições de atividades humanas e estas por si são inesgotáveis. Fiorin (2016) ressalta que os gêneros discursivos só possuem sentido em correlação com sua forma e atividade, desta forma não são isolados em uma determinada esfera de ação, mas são meios de aprender a realidade. Para o autor, tais gêneros, embora apresentem uma estrutura composicional, são mutáveis, transformados pela ação do homem sobre a língua.

Em consonância com os estudos bakhtinianos, Almeida e Pan (2017) anunciam que os gêneros discursivos são práticas sociais próprias a uma dada esfera discursiva, e que esses variam de acordo com seu contexto de utilização e complexidade; desse modo, os gêneros que circulam na universidade também possuem formas próprias de comunicação, diferentes complexidades e interpenetrações, ou seja, variam de acordo com a matéria, a rede teórica, as exigências de cada professor etc. Diante disso, as autoras argumentam que a inexperiência dos alunos perante o uso dos gêneros acadêmicos deveria ser vista como uma característica própria e não como um déficit a ser sanado com medidas compensatórias oferecidas aos alunos da universidade que apresentam supostas dificuldades no uso da língua.

Pode-se inferir a partir desses relatos que a universidade tem exigido dos alunos uma produção científica, mas pouco os orienta para a construção de gêneros acadêmicos, o que está de acordo com Souza e Basseto (2014), quando afirmam que no ambiente universitário a exigência da produção de gêneros acadêmicos nem sempre vem acompanhada do preparo para que essa seja bem sucedida. 
O estudo de Marquesin e Benevides (2011) explicita que o uso da leitura e da escrita na universidade só irá favorecer os estudantes quando possibilitar que esses tenham um papel ativo e responsivo sobre si, sobre os outros e sobre determinados gêneros. Concorda-se com Geraldi (2013) quando esclarece que os professores devem mediar a relação dos alunos com a língua, a fim de que tenham mais autonomia sobre seu uso.

Com relação a causa das dificuldades Beatriz, Vânia e Claudia explicam que essas relacionam-se a sua relação com a escola:

Relação com a escola, faltou alguma coisa, talvez base para me fazer avançar em relação a estas modalidades (Beatriz).

Minha relação com as questões escolares, sempre tive dificuldades desde o Ensino Fundamental (Vânia).

Pelo ensino fragmentado que eu tive, não podia frequentar sempre a escola, então iniciava alguma coisa e eu sempre pegava parte dos conteúdos (Claudia).

Ana e Fernanda esclarecem que as causas de suas dificuldades se relacionam à sua falta de dedicação:

Olha, eu não sei dizer bem os motivos, mas sei que tem muito da falta de dedicação minha nos processos escolares (Ana).

Questão escolar não me dedicava muito e meus pais não acompanhavam de perto meu desempenho escolar (Fernanda).

Com relação às dificuldades com essa modalidade da linguagem é possível observar que algumas participantes atrelam suas causas a um ambiente escolar que pouco favoreceu um uso mais efetivo desta língua, como por exemplo, a falta de acesso a um ensino de qualidade e um ensino fragmentado. Almeida e Pan (2017) chamam atenção para as práticas de leitura e escrita em nosso sistema de ensino, que, em geral, se pautam em uma perspectiva que percebe a língua escrita como mero ato de codificação e decodificação de signos abstratos e fechados entre si, ou seja, a escola trabalha com a leitura e com a escrita a partir de atividades mecânicas e descontextualizadas, baseadas apenas na estrutura normativa da língua.

Algumas participantes, também, explicitaram que suas dificuldades se relacionam à falta de dedicação, comportamentos inadequados ou à falta de acompanhamento familiar para questões referentes à escola. Assim, parece haver um espaço para culpabilização envolvendo o processo de apropriação da linguagem, o qual, segundo Donida e Santana (2019), provoca sofrimentos emocionais, influenciando negativamente a permanência destes sujeitos no ES e desestabilizando seu bem-estar. Estudos recentes (PAN; LITENSKI, 2018; DONIDA; SANTANA, 2019) ressaltam que o sofrimento dos sujeitos relacionado ao uso da escrita 
afasta-os da posição de autores responsivos de suas produções orais e escritas, impossibilitando o desenvolvimento de um pensamento mais crítico e reflexivo frente ao seu papel na comunidade em que se inserem.

Os enunciados das participantes parecem indicar uma lógica medicalizante que naturaliza fenômenos sociais, culturais e históricos em questões médicas ou biológicas, por meio de uma análise isolada e reducionista dos fatores relacionados ao processo de apropriação da linguagem. Tal lógica, segundo Moysés e Collares (2013), consolida uma patologização em todos os níveis de ensino. Nessa direção, Almeida e Pan (2017) alertam para o fato de que o sucesso e o fracasso dos estudantes são explicados, de forma reducionista, a partir do desenvolvimento de habilidades individuais, produzindo, no cotidiano escolar, relações de sofrimento entre os estudantes, os docentes e a própria produção do conhecimento. Signor et al. (2017) esclarecem que a linguagem escrita e sua apropriação ocorrem a partir de um espaço dialógico, no qual a língua não pode ser transmitida, explicitam que as pessoas não recebem a língua pronta para ser usada; mas penetram na corrente da comunicação verbal, que permite que a consciência desperte e comece a operar.

Os enunciados produzidos pelas participantes configuram uma arena de vozes sociais, em que há o embate de diferentes falas (da família, da escola) e posições ideológicas; entende-se assim que os discursos das pessoas estão sempre perpassados por outros discursos que compõem uma rede dialógica contínua (SOBRAL; GUIMARÃES, 2015).

Franco e Molinari (2013) destacam que para que o aluno reconheça a função dialógica das práticas de leitura e escrita, é necessário que participe de atividades significativas com esta modalidade de linguagem, as quais possibilitam que as pessoas reflitam acerca de suas relações com a linguagem escrita.

O segundo eixo diz respeito aos "Efeitos da Oficina de Letramento na posição subjetiva das participantes"; cabe destacar que esse se baseia no entendimento de cada participante acerca de suas produções de leitura e escrita após a participação na oficina do letramento.

\section{Visão das estudantes sobre suas produções de leitura e escrita após a participação na Oficina do Letramento}

Em relação à escrita ajudou muito, principalmente no uso mais apropriado e seguro das palavras, me ajudou a pensar e refletir mais sobre minhas condições, inclusive me ajudou a distanciar-me do uso da escrita como algo só textual/normativo. A oficina causou um impacto, principalmente na 
maneira em que passei a ver as produções escritas e as leituras na Universidade. (Beatriz)

Mudou muito e principalmente mudou pela ação do outro sobre as minhas produções. Na oficina, foi me apresentado o interlocutor, as coisas passaram a ter sentido na hora de usar a fala, leitura e a escrita, essa ação amadureceu minha relação com os diversos discursos. Foi na oficina que a minha escrita passou a ter um sentido na minha vida, me vejo agora como uma pessoa apropriada, sem culpas, em processo de apropriação. (Vânia)

Passei a me ver capaz de usar essas modalidades na minha vida diária. A oficina me auxiliou a entender que muitas queixas que eu tinha, relacionadas à leitura e escrita não pertencem a mim e, sim, a um sistema, um coletivo, parte de um discurso social. (Ama)

Eu passei a ficar mais tranquila mediante o pedido de produzir algo escrito, não tenho mais angústias quando preciso melhorar, mudar (...) passei a assumir minha autoria. (...) Hoje entendo que essas modalidades requerem práticas e que todas as dificuldades que apresentei e ainda apresento, são hipóteses criadas no processo de apropriação dessas modalidades. (Fernanda)

Hoje encaro as práticas de leitura e escrita longe de uma relação de sofrimento. A Oficina mudou a minha visão em relação a mim, que era bem negativa, carregada de angústias e sofrimentos. Hoje é um prazer poder refletir sobre minhas práticas. (Luana)

A oficina me mostrou que essas condições não são só minhas e esse chamado "problema", não era um problema meu e, sim, de um sistema que adoece e faz com que as pessoas se culpabilizem. Passei a me ver como capaz, a oficina me apresentou um mundo de possibilidades e de desejo em relação à leitura e escrita, coisa que a escola me tirou. (Cláudia)

\section{Efeitos da oficina na posição subjetiva frente o uso da leitura e escrita}

Pra mim é como se tivesse melhorado a relação entre mim, a escrita e a leitura. Minhas atividades passaram a ser mais significativas acerca dessas modalidades. (Beatriz)

A oficina me fez perceber e mudar minha posição enquanto sujeito, me deu mais pró-atividade e responsabilidade, passei a existir. (...) Hoje, entendo que estas são criadas em um ambiente de um sistema de ensino elitista e pouco acessivel. (Vânia)

Embora ainda tenha coisas a trabalhar, a oficina me mostrou que temos um problema, e eu não sou o problema. Não é mais dificuldade ler mais de uma vez, arrumei estratégias para me resolver e lidar com estas questões. (Ana).

Via-me como um sujeito em sofrimento, incapaz. Hoje sou autora responsável por minhas produções escritas. (Fernanda)

Hoje me vejo como uma boa leitora, curiosa e passei a ver minhas condições de maneiras diferentes. Não são mais vistas como dificuldades que me incapacitam nem impossibilidades. (Luana)

A oficina me deu asas para voar, esse sempre foi meu desejo. Com minha entrada, eu comecei a me sentir capaz, passei a me ver com possibilidades, inclusive possibilidades de enfrentar as condições que apareceram e aparecem durante a estadia na Universidade. O Letramento criou uma ponte entre mim e o abismo que tinha na minha frente quando entrei na graduação. (Cláudia) 
Com relação à visão das estudantes sobre suas produções de leitura e escrita após a participação na Oficina do Letramento, os enunciados elaborados pelas participantes indicam que na oficina houve uma mudança frente às suas práticas de leitura e escrita, assim, puderam valorizar suas histórias e seus saberes, superando situações cotidianas limitantes e participando mais amplamente da comunidade acadêmica. Além disso, nota-se uma desculpabilização perante as "queixas", como no relato a seguir - Bom, a oficina me mostrou que essas condições não são só minhas e esse chamado "problema", não era um problema meu e, sim, de um sistema que adoece e faz com que as pessoas se culpabilizem. Destaca-se, neste eixo, que após a participação em um trabalho com e sobre a linguagem, pautado em uma perspectiva dialógica, houve uma ampliação das reflexões das alunas acerca do uso da linguagem escrita. Percebe-se em vários relatos apresentados que as estudantes passaram a apresentar uma posição discursiva mais responsiva a respeito de suas condições de apropriação dos gêneros circulantes no ambiente universitário. Um exemplo pode ser visualizado no seguinte excerto - A oficina causou um impacto, principalmente na maneira em que passei a ver as produções escritas e as leituras na Universidade. A meu ver, estas práticas passaram a ter um sentido, um destinatário, um interlocutor, que faz a ponte entre o eu e o outro que está ausente.

Os enunciados apresentados indicam que a oficina trouxe efeitos positivos para as participantes, que passaram a refletir sobre suas posições dialógicas, sobre o lugar responsivo que podem ocupar e a possibilidade de ter uma posição mais autônoma no processo da escrita acadêmica, tal como no seguinte enunciado - Via-me como um sujeito em sofrimento, incapaz. Hoje sou autora responsável por minhas produções escritas. Nota-se, ainda, uma ampliação da visão sobre as práticas de leitura e escrita, a partir da sua dimensão discursiva e não apenas normativa. Além disso, é possível ressaltar o impacto positivo que a Oficina da promoção do letramento teve na possibilidade de falar de si, e na maneira com que cada uma das envolvidas se sentiu em relação às suas escolhas e ao modo de agir na universidade.

As participantes, que anteriormente referiam uma relação negativa com a linguagem escrita, baseada em sofrimentos e angústias, passaram a entender que sua condição não era única, e que o sistema educacional brasileiro, em geral, trabalha com a língua, especialmente, a partir de sua estrutura, em detrimento de seus aspectos discursivos. Alguns relatos estão em consonância com dados apontados no estudo de Pan e Litenski (2018), que indicam que, no ambiente do ES, ler e escrever são atividades que garantem apropriação dos gêneros que circulam ali, responsáveis pela própria formação profissional. Segundo as autoras, há necessidade de discutir a respeito das experiências negativas frente à leitura e escrita em um 
espaço como nas oficinas de letramento, as quais auxiliam no processo de desconstrução dos discursos que individualizam as queixas de leitura e escrita. Dessa forma, é possível afirmar que ao propor atividades significativas a partir de textos orais e escritos, a Oficina de Letramento teve impacto em relação à autoria, autonomia e responsividade das participantes, possibilitando mudanças positivas na relação que estabelecem com a leitura e a escrita de diferentes gêneros, dentre esses o acadêmico.

Nessa direção, a Vânia, participante da pesquisa, afirmou que, na Oficina, ela passou a existir, na medida em que percebeu sua posição responsiva. Também a Ana relatou que entendeu que suas supostas dificuldades não eram individuais e a Claudia referiu que o efetivo trabalho com a leitura e a escrita criou uma ponte capaz de levá-la a perceber-se como parte integrante da sua própria formação acadêmica. Essas afirmações evidenciam que a Oficina de Letramento é um espaço que promove atividades significativas com a linguagem escrita, alterando positivamente a possibilidade de participar do cotidiano universitário.

\section{Considerações finais}

Por meio desse relato de pesquisa foi possível evidenciar que muitos estudantes carregam em suas histórias acadêmicas uma visão negativa com relação à sua autoria e autonomia, além de sofrimentos frente às práticas de leitura e escrita. Assim, reproduzem discursos sociais que culpabilizam apenas a si mesmos, indo de encontro a discursos homogeneizadores e normalizadores, os quais não levam em consideração a história de cada sujeito.

A partir de um trabalho de promoção do letramento no ambiente universitário, pode-se discutir a importância de dialogar a respeito dessa temática em um espaço que pode contribuir para a desnaturalização das dificuldades dos estudantes como individuais, bem como a efetivação de atividades dialógicas que possibilitam um efeito positivo na posição subjetiva dos sujeitos. Tal espaço, levando em consideração o contexto social, cultural e histórico no qual cada pessoa está inserida, pode permitir que seus participantes assumam outras posições frente às suas supostas dificuldades, possibilitando a ampliação de sua autonomia, autoria e uma diminuição de suas angústias e sofrimentos frente à linguagem escrita.

Dessa forma, é preciso ressaltar a relevância de trabalhos na universidade que considerem práticas dialógicas e assumam um compromisso, a partir de uma posição contrária aos discursos patologizantes medicalizantes que culpam o aluno por seu fracasso acadêmico, 
em oferecer aos discentes a possibilidade de atuarem de maneira mais responsiva nos contextos sociais em que estão inseridos.

AGRADECIMENTOS: À Coordenação de Aperfeiçoamento de Pessoal de Nível Superior (CAPES), pela disponibilização de financiamento que resultou na elaboração desse estudo.

\section{REFERÊNCIAS}

ALMEIDA, A. B.; PAN, M. A. G. S. Contribuições bakhtinianas para o estudo das práticas de leitura e escrita na universidade: autoria, gêneros científicos e identidade profissional. In: PAN, M. A. G. S.; ALBANESE, L.; FERRARINI, N. L. (Org.). Psicologia e educação superior: formação e (m) prática. Curitiba: Juruá, 2017. p. 75-98.

BAKHTIN, M. M. Estética da criação verbal. São Paulo: Martins \& fontes, 2003. 512 p.

BAKHTIN, M. M. Marxismo e Filosofia da Linguagem. São Paulo: HUCITEC, 2006. 193 p.

BRASIL. Ministério da Educação. Censo de educação superior: novas notas estatísticas. Brasília: MEC, 2018.

CANGUILHEM, G. O normal e o patológico. Rio de Janeiro: Forense Universitária, 2000.

DONIDA, L. O.; SANTANA A. P. Apoio pedagógico como proposta de educação para todos. Revista Educação e Pesquisa, São Paulo, v. 45, e.192527, p. 1-19, 2019.

FIORIN, J. L. Introdução ao pensamento de Bakhtin. São Paulo: Contexto, 2016. 160 p.

FRANCO, A. S.; MOLINARI, C. A leitura e a escrita na universidade. Revista Eletrônica Pesquisa educação, Santos, v. 5, n. 10, p. 276-294, 2013.

FUZA, A. F.; FIAD, R. S.; GOMES, L. N. Letramento de acadêmicos do curso de letras: apropriação de gêneros e implicações para a formação do professor. Interface, v. 6, n. 1, p. 37-45, 2015.

GERALDI, J. W. Portos de passagem. São Paulo: Martins \& Fontes, 2013. 288 p.

GIROTO, C. R. M.; ARAUJO, L. A.; VITTA, F. C. F. Discursivização sobre "doenças do não aprender" no contexto educacional inclusivo: o que dizem os professores de Educação Infantil? Revista Ibero-Americana de Estudos em Educação, Araraquara, v. 14, n. esp. 1, p. 807-825, 2019.

INSTITUTO ABRAMUNDO. ILC - Indicador de Letramento Científico: sumário executivo de resultados. São Paulo: Fundação Carlos Chagas em Parceria com Instituto Paulo Montenegro; Ação Educativa, 2014. 
INSTITUTO PAULO MONTENEGRO. Indicador de Alfabetismo funcional: estudo especial sobre alfabetismo e mundo do trabalho. 2016.

KERSCH, D. F.; SANTOS, F. C. Escrita acadêmica e desenvolvimento de autoria na formação de professores via EaD: As universidades estão preparadas. Revista Raído. Dourados, v. 11, n. 25, p. 89-106, 2017.

MARQUESIN, D. F. B.; BENEVIDES, C. R. Leitura e Escrita no ensino superior. Revista Brasileira de educação, Rio de Janeiro, v. 14, n. 1, p. 9-28, 2011.

MARTINS, M. S. C. Letramento acadêmico e oralidade: repensando termos à luz da presença Indígena nas universidades brasileiras. Revista Scripta, Belo Horizonte, v. 21, n. 43, p. $127-$ $147,2017$.

MASSI, G. et al. Active aging: an intervention-research report. Rev CEFAC, v. 20, n. 1, p. 5$12,2018$.

MORETTO, M. Tentativas de apropriação da linguagem acadêmica por estudantes

universitários: A produção escrita na universidade. Comunicações, Piracicaba, v. 24, n. 1, p. 171-186, jan./abr. 2017.

MOYSÉS, M. A. A.; COLLARES, C. A. L. Medicalização: o obscurantismo reinventado. In: COLLARES, C.; MOYSÉS, M. A.; RIBEIRO, M. C. (Org.). Novas capturas, antigos diagnósticos na era dos transtornos: memórias do II Seminário internacional educação medicalizada: dislexia, TDAH e outros supostos transtornos. Campinas, SP: Mercado de Letras, 2013. p. 41-64.

PAN, M. A. G. S.; LITENSKI, A. C. L. Letramento e identidade profissional: reflexões sobre a leitura, escrita e subjetividade na universidade. Revista Psicologia escolar e educacional, São Paulo, v. 22, n. 3, p.527-534, 2018.

SIGNOR, R. Os gêneros do discurso como proposta de ação fonoaudiológica voltada para sujeitos com queixas de dificuldades de leitura e escrita. Bakhtiniana, São Paulo, v. 1, n. 5, p. 54-71, 2011.

SIGNOR, R. C. F.; BERBERIAN, A. P.; SANTANA, A. P. A Medicalização da Educação: Implicações para a constituição do sujeito/aprendiz. Revista Educação e Pesquisa, São Paulo, v. 43, n. 3, p. 743-763, 2017.

SOUZA, M. G.; BASSETTO, L. M. T. Processo de apropriação de gêneros acadêmicos por graduandos em letras e as possíveis implicações para formação de professores/pesquisadores. RBLA, Belo Horizonte, v. 14, n. 1, p. 83-110, 2014.

WINIARSKI, L. R. S. Gêneros acadêmicos e a formação no ensino superior: visão de um grupo de discentes de fonoaudiologia. 2018. 42 f. Monografia (Trabalho de Conclusão do Curso de Fonoaudiologia) - Faculdade de Ciências Biológicas e de Saúde, Universidade Tuiuti do Paraná, Curitiba, 2018. 


\section{Como referenciar este artigo}

PÔRTO, T. M.; MASSI, G. A.; GUARINELLO, A. C. A relação de alunos de fonoaudiologia com a leitura e escrita a partir de uma oficina de letramento. Revista Ibero-Americana de Estudos em Educação, Araraquara, v. 15, n. esp. 5, p. 2985-3000, dez. 2020. e-ISSN: 19825587. DOI: https://doi.org/10.21723/riaee.v15iesp5.14570

Submetido em: 10/01/2020

Revisões requeridas em: 25/05/2020

Aprovado em: 30/10/2020

Publicado em: 01/12/2020 